Li, Q., Li, C., McCabe, S., \& Xu, H. (2019, forthcoming). ALWAYS BEST OR GOOD ENOUGH? The effect of 'mind-set' on preference consistency over time in tourist decision making. Accepted for publication in Annals of Tourism Research 07/01/2019.

Author's Name: Qiuyun Li

Affiliation: College of Tourism and Service Management, Nankai University, Jinnan Campus, No. 38, Tongyan Road, Tianjin, 300350, China.

Email Address: 930227160@qq.com

Telephone Number: +8616622899171

Fax Number: $+86(022) 23012055$

Author's Name: Chunxiao (Spring) Li*

Affiliation: College of Tourism and Service Management, Nankai University, Jinnan Campus, No. 38, Tongyan Road, Tianjin, 300350, China.

Email Address: xiaoxiao1985214@hotmail.com

Telephone Number: +8618322125502

Author's Name: Professor Scott McCabe

Affiliation: Nottingham University Business School, Jubilee Campus, Wollaton Road, Nottingham, NG8 1BB, United Kingdom.

Email Address: Scott.McCabe@nottingham.ac.uk

Telephone Number: +44 (0) 1158466683

Author's Name: Professor Hong Xu

Affiliation: College of Tourism and Service Management, Nankai University, Jinnan Campus, No. 38, Tongyan Road, Tianjin, 300350, China.

Email Address: xuhonhg@126.com

Telephone Number: +8618622940636

* = Corresponding Author 


\title{
ALWAYS BEST OR GOOD ENOUGH? The effect of 'mind-set' on preference consistency over time in tourist decision making.
}

\begin{abstract}
Where a lengthy period is available for the choice of tourist destination, people's tendency to change their minds can be pronounced. This makes the investigation of preference (in)consistency of great interest. Here, we integrate construal level theory (CLT) with mind-set theory, for the first time, to explore the moderating effect of an internal factor (i.e. mind-set) on preference shifts from desirable to feasible attributes over time. The results of four choice experiments suggest that, compared with people with a satisficing mind-set, people with a maximizing mind-set are reluctant to sacrifice desirability for feasibility, which counters the inclination to alter preferences as the decision time approaches. Furthermore, we found that different preference patterns between maximizers and satisficers are not connected to desirability but result from maximizers' consistency in placing less importance on feasibility. Implications for future studies and destination marketers are outlined.
\end{abstract}

KEYWORDS: destination choice; temporal distance; construal level theory; satisfying and maximizing mind-set.

\section{INTRODUCTION}

Most tourism activity takes place in the mind. We spend long months of the year dreaming about, planning and anticipating our next holiday, and much time reminiscing afterwards, looking back fondly (or ruefully) on those experiences. Thus, unlike general consumption contexts, holiday (destination) choice is usually an elaborate and lengthy process, during which tourists' preferences are likely to change before a final decision is made. Yet much of the existent research on destination choice has adopted a cross-sectional approach, and therefore overlooked this dynamic process. Few studies have examined how tourists' preferences change over the course of a period of decision making. Recently, notable efforts have been made to address this gap through the development of construal level theory (CLT) to explain dynamic patterns in preferences (Basoglu \& Yoo, 2015; Tan, 2018). CLT proposes that, in general, tourists' preferences shift from desirability (e.g. beautiful scenery or exotic culture) to feasibility (e.g. trip costs or destination accessibility) as they progress through the different stages of consideration and deliberation (Basoglu \& Yoo, 2015; Tan, 2018). However, this promising avenue of research is at an emergent stage, and raises many more questions for further research. For example, to what extent are tourists willing to compromise between desirability and feasibility during their decision-making process? Do all tourists follow the same type of shift over time in their pattern of preferences in this regard? If not, why not?

These questions are theoretically and practically important for the following reasons. Firstly, consumers are interested in maximizing long-term happiness (Zhao, Hoeffler, \& Zauberman, 2007). Time-dependent changes in preferences (in terms of desirability versus feasibility), however, may result in failure to follow through with previously committed choices, which in turn can lead to regret and dissatisfaction (Soman, 2004; Lee \& Zhao, 2014). An understanding of the dynamic process of change in preference would not only be of practical value but, more importantly, could shed light on how to control or prevent negative the consequences of 
inconsistencies in preferences. Additionally, from a destination marketing perspective, a more detailed understanding of the patterns of change in tourists' preferences could increase the effectiveness of marketing campaigns by targeting different stages of decision making and messages that specifically focus on tourists' preference transition from desirability to feasibility issues.

In order to explore the way tourists' preferences shift over time, this study introduces a key concept, 'mind-set', which is an individual's general way of thinking when making decisions or responding to situations (Ma \& Roese, 2014). Previous research has demonstrated that individuals differ in their approach to decisions. Some people aim to maximize outcomes in choice situations, and hence are termed 'maximizers' (Ma \& Roese, 2014), whereas others, in contrast, are willing to accept a 'good enough' outcome, and are therefore called 'satisficers' (Schwartz et al., 2002). Recent research that compared individuals with either a maximizing or satisfying mind-set found that the latter were more willing to compromise desirability for feasibility (Luan \& Li, 2017), which points to the possibility that tourists differ in the extent to which their preference structure involves compromise. Because tourist destination choice is usually a lengthy and dynamic decision-making context, our understanding of tourists' preferences requires a longitudinal perspective. By integrating construal level theory with mind-set theory, this study aims to discover a critical internal factor determining changes in individual preferences over time. Thus, we aim to contribute to the development of a more comprehensive and accurate theory of destination choice. Significantly, our study aims to shed light on one small facet of the 'black box' of the mental processes underpinning consumer choice, which demonstrates how we might counteract the effects of temporal distance on preferences, leading potentially to more optimal outcomes for consumers in the future.

\section{LITERATURE REVIEW AND HYPOTHESIS DEVELOPMENT}

\section{CLT and dynamic change in tourists' preferences}

Research on destination choice has been a cornerstone of tourism studies. As a complicated and lengthy process (Jeng \& Fesenmaier, 2002), tourists' choice is very likely to alter over time. Dynamic change in consumer preferences has been subjected to detailed investigation in other fields, including: behavioural decision making (e.g., Thaler, 1981); consumer research (e.g., Lee \& Zhao, 2014; Zhao et al., 2007); and marketing (e.g., Eyal, Liberman, Trope, \& Walther, 2004; Liberman, Sagristano, \& Trope, 2002; Trope \& Liberman, 2003; Trope, Liberman, \& Wakslak, 2007). Despite this, though, there has been limited application in tourism studies. Most previous research on tourists' preferences has been based on a cross-sectional approach (e.g. Seddighi \& Theocharous, 2002; Hsu, Tsai, \& Wu, 2009) in which preferences are estimated statistically at a certain point in time. However, there have been increasing calls for a process approach to research on destination choice (Smallman \& Moore, 2010; McCabe, Li, $\&$ Chen, 2016). Some studies have explored the dynamics of tourists' preferences based on choice set theory (Decrop, 2010; Li, McCabe, \& Li, 2017). Yet, the focus of much of this research has been on the stages of decisions rather than on uncovering and explaining the patterns of such changes per se. 
In order to explain the cognitive mechanism behind dynamism in preferences, construal level theory (CLT) has been developed in consumer and marketing research (e.g., Dhar \& Kim, 2007; Goodman \& Malkoc, 2012). CLT proposes that temporal distance influences the mental representation of future events (Liberman \& Trope, 1998). Actions in the distant future are more likely to be represented in terms of abstract and central features (high-level construal). However, representations of near-future events are more concrete and focus on peripheral features (lowlevel construal). This shift in mental representation can change an individual's preference for particular attributes (Zhao et al., 2007). Due to its explanatory power for mental processes, scholars have recently begun to adopt this theory to investigate tourism problems, such as the gap between travel intention and action (Kah, C. K. Lee, \& Lee, 2016), hotel selection (Basoglu \& Yoo, 2015), promotion strategies (J. Kim, P. B. Kim, Kim, \& Magnini, 2016), and destination image (Tan, 2018).

The promise offered by CLT suggests that it would also be useful in the investigation of destination choice. Destination choice is a negotiation process between a tourist's needs and the destination's offer (Ankomah, Crompton, \& Baker 1996). While many previous studies have focused on tourists and their motivations, attitudes, needs or perceptions of destinations, destination attributes are rarely examined beyond destination image research. One reason for this lack of quantitative studies may be the methodological challenge of capturing the multiplicity of destination features that are considered by tourists in their destination decision making process (Karl \& Reintinger, 2017). Because the nature and number of attributes considered may vary greatly among individuals (Dryglas \& Salamaga, 2017), it is hard to balance comprehensiveness of attributes and feasibility of the research design. This study simplifies the multiplicity of attributes by employing only two 'must-have' categories: desirability and feasibility.

Desirability refers to the "why" of an action (goals, motives), whereas feasibility refers to the "how" (instrumental and situational factors such as costs and constraints). For example, climbing Mount Everest may be highly desirable to a person, offering self-actualisation, goal attainment and excitement, but it may not be feasible due to the mountaineering expertise required, high costs and so on. Liberman and Trope (1998) found that in goal-directed activities, desirability of the activity's end state represents a high-level construal, whereas the feasibility of attaining this end state represents a low-level construal. According to CLT, desirability considerations are assigned more weight than feasibility considerations in distant future events, whereas the reverse is true in near future events. In the consumer behaviour literature, product choices have been demonstrated to involve trade-offs between desirability (i.e., functionality of a product) and feasibility (i.e., convenience of use). Research has shown that consumers tend to prefer products high in desirability (greater functionality) when they make their choice for the distant future but switch their preferences to products high in feasibility (greater convenience) when making a decision that has immediate consequences (Zhao et al., 2007; Lee $\&$ Zhao, 2014). Recent research has explored this proposition for the formation of destination image. Tan (2018) found that, generally, tourists think of a destination's desirable attributes for a visit in the distant future, whereas feasibility image characteristics become more salient as the trip nears. As a result, we propose the following hypothesis: 
H1: Temporal distance influences tourists' preference for either desirability or feasibility in choice of destination.

H1a: For an intended trip further in the future, tourists prefer destinations with stronger desirable attributes than destinations with stronger feasible attributes.

H1b: For a trip intended to be taken sooner, tourists prefer destinations with stronger feasible attributes than destinations with stronger desirable attributes.

\section{The moderating effect of mind-set on preference change}

Desirability and feasibility are two sides of destination choice. In the choice-goals framework, Bettman, Luce and Payne (1998) argue that the pursuit of desirability and feasibility are consistent with value-related and effort-related goals, respectively. That is, desirability refers to the valence of an action's end state, whereas feasibility refers to the ease or difficulty of reaching the end state (Liberman \& Trop, 1998). Although individuals tend to compromise on desirability for a near-future event since the low-level construal is predominant in this context, the trade-off between desirability and feasibility may result in cognitive dissonance. If a tourist chooses to give up a desirable destination to opt for a more feasible one, he/she may experience regret and dissatisfaction (Soman, 2004; Lee \& Zhao, 2014). Consequently, researchers have investigated how to counteract preference inconsistency. Various counteractive interventions have been proposed, such as attention shifting (Hoch and Loewenstein, 1991; Mischel, Shoda, \& Rodriguez, 1989), practising mental simulation (Zhao et al., 2007), and highlighting price information (Lee \& Zhao, 2014). Most of these studies, however, focused on external interventions rather than the decision maker's internal variables. In fact, the weights people place on desirability and feasibility factors are highly related to their mind-set (Luan \& $\mathrm{Li}$, 2017). Indeed, we can propose that an individual's mind-set influences their eventual choices, such that individuals with a maximizing mind-set choose different destinations than those with a satisfying mind-set.

Accordingly, a maximizing mind-set is conceptualized as an effort to choose the best rather than settling for good enough options (Ma \& Roese, 2014). The outcomes of a misalignment between mind-set and an optimal decision are negative emotions, such as regret and dissatisfaction, which are amplified in the case of maximizers if the choice is not optimal (Ma \& Roese, 2014). In order to make optimal decisions, maximizers are willing to engage in an exhaustive search of all possible options, investing substantial time and effort in decision processes (Iyengar, Wells, \& Schwartz, 2006). On the other hand, satisficers have an internal threshold of acceptability against which they evaluate options, and will choose an outcome falling above that threshold. Therefore, satisficers are content to settle for a good enough option - not necessarily the very best outcome in all respects. In prior research on maximization, the valence of the choice and the effort expended to reach the outcome were always considered together (e.g., Dar-Nimrod, Rawn, Lehman, \& Schwartz, 2009; Iyengar et al., 2006). A recent study, however, found that, compared with satisficers, maximizers are less likely to sacrifice desirability because they focus purely on value-related goals and pay less attention to effortrelated goals (Luan \& Li, 2017).

Here, we extend this theory by assuming that the further away in time a person is from action, 
high-level construal is activated, and individuals are more inclined to focus on desirability (i.e. value-related goals). Under such conditions, regardless of whether individuals are maximizers or satisficers, destinations with stronger desirable attributes are preferred to than destinations with stronger feasible attributes. However, when temporal distance is less, low-level construal is activated and effort-related goals are prioritised. Yet, individuals with a maximizing mindset - who care much less about effort-related goals than satisficers - should still prefer desirable above feasible destinations. In contrast, individuals with a satisfying mind-set should prefer destinations with feasible attributes, given their concern for effort-related goals. The following hypothesis represents this theory:

H2: Tourists' mind-set (maximizing or satisfying) moderates the influence of temporal distance on destination preference.

H2a: In a situation with greater temporal distance, individuals with both types of mind-set prefer destinations with higher desirability attributes to destinations with higher feasibility attributes.

H2b: In a situation characterised by closer temporal distance, tourists with a maximizing mindset retain consistent preferences, whereas those with a satisfying mind-set shift their preference to more feasible destinations.

According to Luan and Li (2017), satisficers and maximizers do not differ in terms of the importance they place on desirability, but rather the importance they place on feasibility. According to the CLT, high-level construal predominates when the ultimate decision is more distant temporally (Liberman \& Trope, 1998). Thus, under such conditions, both maximizers and satisficers pay more attention to desirability because the consideration of feasibility is supressed and desirability is valued highly. As time for the decision approaches, when the lowlevel construal is activated, both maximizers and satisficers begin to consider issues related to feasibility. But since maximizers place much less importance on feasibility than satisficers, their inclination to compromise their original plans should be much less than that of satisfciers. This difference in turn leads to profound differences in changes in preference. Building on this assumption, we propose that the importance of feasibility is also the mediator of the moderating effect of mind-set on change in preference over time. This leads us to the following hypothesis:

H3: The importance placed on the feasibility characteristics of destinations mediates the effect of tourist's mind-set on temporal distance and destination preference.

\section{Estimation methods of tourism destination preference}

In early research, in order to understand destination preferences, researchers tended to utilize a simple survey asking respondents to scale or rate each relevant attribute according to its importance (e.g. Haahti, 1986, Um \& Crompton, 1990, Go \& Zhang, 1997). Later, more advanced methods were adopted to explore the substitutive effect/importance of each attribute such as: AHP analysis (analytic hierarchy process) (e.g., Hsu et al., 2009), conjoint analysis (e.g., Ciná, 2012), and discrete choice experiments (Sarman, Scagnolari, \& Maggi, 2016). Discrete choice experiments are very similar to choice-based conjoint analysis. The basic 
procedure is to present a set of combinations of different attribute levels/aspects involved in destination choice to respondents and then ask them to choose their preferred alternatives from the stimuli set (Chaminuka, Groeneveld, Selomane, \& Van Ierland, 2012; Li, McCabe, $\&$ Song, 2017). Based on respondents' preferences, the part-worth utility of attributes (or attribute aspects) can be calculated through various regressions. Experimental design allows researchers to investigate the attributes that may or may not be provided by particular destinations, which is of great help for revealing potential preferences (Chaminuka et al., 2012).

Although these methods have yielded rich information on tourists' destination preferences, most previous studies imply a static preference by their use of cross-sectional analyses. Although notable exceptions do exist (e.g. Li et al., 2017, in which the role played by each attribute at different stages of decision making was studied by utilizing a computer program), relatively little effort has been made to quantify whether tourists' preferences for selected attributes change over time. This is probably due to the complexity of data collection and analysis techniques required, as well as confounding factors that might influence any changes in tourist preference.

Recently, the use of behavioural experiments in tourism research has emerged, providing useful techniques to understand how tourists respond to various behavioural cues or stimuli, especially in understanding drivers of pro-environmental or sustainable behaviours (e.g. Araña \& León, 2016; Doran, Hanss, \& Øgaard, 2017). Yet, compared with conventional crosssectional surveys, experimental studies that quantify the effects of independent stimuli on behavioural responses remain in their infancy (Dolnicar \& Ring, 2014). The choice of experimental design is important, since researchers can manipulate independent variables to determine the time-ordering of the causal relationship and use controls such as randomization to eliminate alternative explanations (Highhouse, 2009; Friedman \& Sunder, 1994). Consequently, this study utilized four experiments with different destination choice scenarios that involved desirability/feasibility trade-offs to try to capture robust results. Moreover, through manipulation of different temporal distances, this study was able to uncover dynamic change in destination preference at different stages of decision making. The detailed procedures of these experiments are presented below together with the explanations of the experimental designs.

\section{EMPIRICAL APPROACH}

The four experiments were designed to test our hypotheses as follows. Firstly, the effect of mind-set on destination choice over time was investigated through the first three experiments. The last experiment further tested whether the perceived importance of feasibility explains differences in preference patterns over time. 
Experiment 1 serves two purposes: to test the effect of temporal distance (near future versus distant future) on destination preference regarding desirability and feasibility (H1); and to provide evidence on whether individuals with different mind-sets differ in their preference consistency over time (H2). Mind-set was measured in this experiment by the adoption of the Maximization Scale developed by Schwartz et al. (2002) and Nenkov, Morrin, Schwartz, Ward, \& Hulland (2008).

Experiment 2 was designed to provide further evidence on whether mind-set influences tourists' patterns of preference change. In Experiment 2A, preference was measured by the amount of money tourists would pay for the desired destination, whereas the amount of time tourists would be prepared to wait before being able to make the visit was used to measure preference in Experiment 2B. Furthermore, in order to add practical value to the study, mind-set was not simply measured in experiment 2 as an inherent trait, but was activated in order to determine the possibility of manipulating tourist mind-set in actual marketing campaigns.

To ensure the ecological validity of our findings, an actual tourism destination (Tibet) instead of a fictional one was used in Experiment 3. In addition, the manipulation of temporal distance was achieved indirectly in most previous studies by asking respondents to imagine that the decision needed to be made in the near or far future. This study adopted a direct manipulation of temporal distance in this experiment by asking students about their intended graduation trips across different grades (junior students vs. senior students). The timing of Experiment 3 was intentional, since senior students were about to graduate within two weeks and junior students had another year before their own graduation.

Experiment 4 replicated and generalized the results of the first three experiments by using images of real destinations to create a more vivid impression for respondents. More importantly, the main objective of Experiment 4 was to further explain why a difference in mind-set might lead to different degrees of preference inconsistency. Based on a previous study (Luan \& $\mathrm{Li}$, 2017), we proposed that the difference in importance placed on feasibility leads to different patterns of preference change between groups (H3). Experiment 4 was designed to test this proposition. To increase the external validity of this research, a non-student sample was adopted through an online experiment.

\section{EXPERIMENT 1}

\section{Method}

Design and procedures. A total of 207 students (135 females, 72 males, $M_{\text {age }}=20.31, S D=$ 2.276) at a large university in China were recruited for participation. This experiment adopted a between-subjects design to test the effects of temporal distance and maximizing tendency. The subject's preference for options of high-feasibility or high-desirability destinations served as the dependent variable.

In order to avoid the influence of other factors related to actual destinations, fictional destinations were used for this experiment. We developed the destination materials by the 
following steps. Firstly, 10 in-depth interviews were conducted to identify the range of desirable and feasible attributes perceived by participants. All of the interviewees had prior independent destination decision-making experience and were in the age range 19 to 28. Based on the interviews and desk research of relevant studies (e.g. Liberman \& Trope, 1998; Trope \& Liberman, 2010; Baskin, Wakslak, Trope, \& Novemsky, 2014), descriptions of two destinations were developed. Four attributes were referred to in each description: scenery, activities, airplane ticket and local language. Destination A was described as an option high in desirability (e.g. the water is crystal clear and the activities are rich) but average in feasibility (e.g. no discount for the airplane ticket), whereas destination $\mathrm{X}$ was described as high in feasibility but moderate in desirability (see Appendix A). Secondly, to ensure that these two destinations differed significantly on feasibility and desirability, a pretest was conducted. 88 respondents (53 females, 35 males, $M_{\text {age }}=29$ ) who were not involved in any of the main experiments were recruited through an online survey company. They were requested to read the descriptions and then rate the desirability and feasibility of each destination respectively on a 7-point scale ( $1=$ not desirable/feasible at all, 7 = very desirable/feasible). The results showed that the desirability $(M=5.69)$ of destination A was significantly higher than that of destination $\mathrm{X}(M=4.72, F(1,174)=24.488, p<.001)$ whereas the feasibility $(M=4.93)$ of destination A was significantly lower than that of destination X $(M=5.66, F(1,174)=29.411, p<.001)$.

Respondents were asked to imagine that they were going on vacation in either one week (near future) or one year (distant future) and, after careful selection, only two seaside destinations remain, destination $\mathrm{A}$ and destination $\mathrm{X}$. The descriptions of the two destinations were then presented to the respondents. After reading the material, participants were asked to indicate their relative preference on a seven-point scale anchored at the preference of destination A (= 1 , the desirable but not feasible option) and destination $\mathrm{X}(=7$, the feasible but not desirable option). The two destinations were presented in a random order, and the preference scores were unified for further analysis, whereby higher scores indicated higher preferences for the highfeasibility and low-desirability option.

As a manipulation check for time, we asked participants to rate their perception of the temporal distance (one week vs. one year) on a 7-point scale $(1=$ very near vs. $7=$ very far). Then the respondents were required to complete a short form of the Maximization Scale (Schwartz et al., 2002; Nenkov et al., 2008) to test for maximizing tendency. Six items were included in the Scale and each item was rated on a seven-point scale ( 1 = strongly disagree, $7=$ strongly agree). Demographic questions and questions regarding participants' previous travel experience were also asked.

\section{Results and discussion}

Our manipulation of time was successful in showing that participants perceived that a temporal distance of one week $(M=2.85)$ is significantly shorter than that of one year $(M=4.44, F(1$, $205)=89.067, p<.001)$. We used the same manipulation check for later experiments, and our time manipulation was consistently confirmed. Therefore, we do not report this measure for the later experiments. 
We conducted a hierarchical linear regression (Raudenbush, Bryk, \& Congdon, 2004) on the relative preference using a dummy variable for temporal distance $(1=$ distant future, $0=$ near future) and maximization tendency, using their interactions as the independent variables and previous travel experience as a control variable.

The main effect of temporal distance on preference was significant, $\beta=-0.215, t(202)=-3.332$, $p=.001$, showing that as temporal distance increases, preference for higher feasibility/lower desirability decreases. The main effect of the maximizing tendency on preference was also significant, $\beta=-0.270, t(202)=-4.044, p<.001$, indicating that satisficers' preferences for the higher-feasibility/lower-desirability options were higher than maximizers. More importantly, there was a significant temporal distance $\times$ maximization tendency interaction effect, $\beta=0.170$, $t(202)=2.574, p=.011$. In order to reveal the essence of the interaction effect, simple effect analysis was conducted with temporal distance (near vs. distant future) and mind-set (maximizer $\left(M_{\text {maximization tendency }}-1 S D\right)$ vs. satisficer $\left(M_{\text {maximization tendency }}+1 S D\right)$ ). The effect analysis suggested that temporal distance has a marginally significant effect on preference for participants with a satisfying mind-set $(F(1,55)=3.02, p=.088)$, whereby those who engaged in the near future condition indicated a significantly greater preference for the higherfeasibility/lower-desirability destination $(M=5.14)$ than those in the distant future condition $(M=3.34)$. However, for participants with a maximizing mind-set, there was no significant difference regarding preferences between the near future condition $(M=2.94)$ and the distant future condition $(M=2.69, F(1,55)=.77, p=.383)$. As depicted in Fig. 1, satisficers $(-1 S D)$ in the near-future condition preferred the higher-feasibility/lower-desirability option but higher-desirability/lower-feasibility option in the distant-future condition. However, maximizers $(+1 S D)$ always preferred the higher-desirability/lower-feasibility option, whether in the near or distant future conditions.

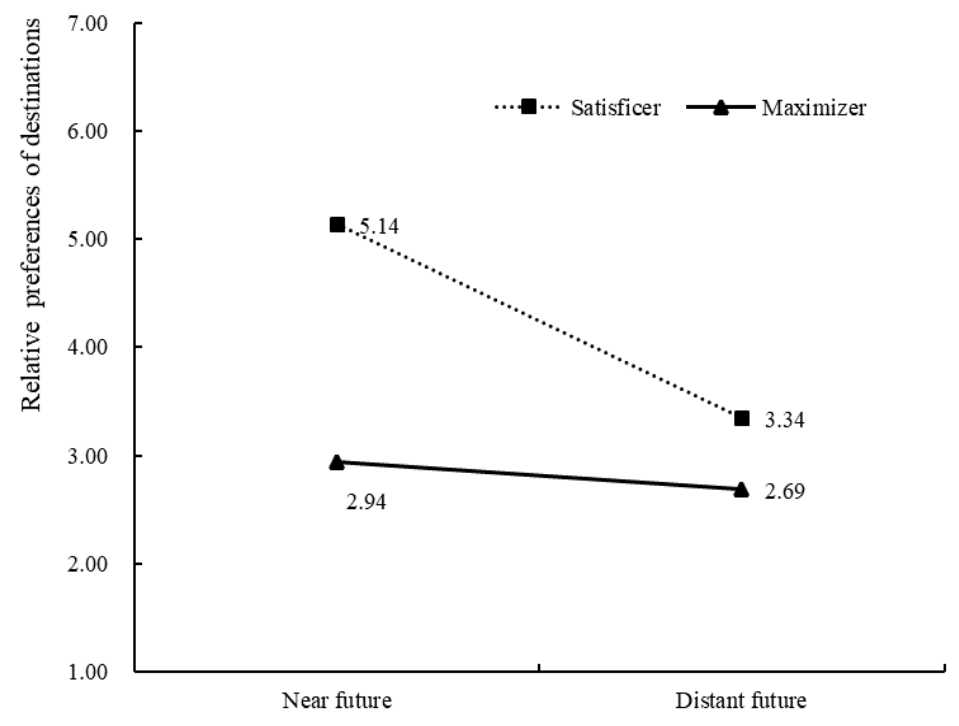

Notes: A higher score represents greater preference for the higher-feasibility option. Covariate appearing in the model is evaluated at the following value: Previous travel experience $=1.674$. 
Figure 1. Experiment 1: Relative preference in destinations by temporal distance.

Experiment 1 provided initial support for our hypothesis 1 and hypothesis 2 . Consistent with CLT, in general, participants preferred the high-desirability destination in the distant future and the high-feasibility destination in the near future. These results also test propositions made in previous qualitative tourism studies. Um and Crompton (1992) found that facilitators were most influential in whether a potential destination was preferred earlier in the decision making, whereas inhibitors were most influential later. Decrop and Snelders (2004), through longitudinal interviews, revealed that as the vacation approached, destination plans tended to move from fantasy to reality and people became more aware of the need to make relevant "sacrifices". Although the general characteristics of dynamic preferences are understood, the influencing factors involved have been rarely examined. Experiment 1 advances this knowledge, finding that an individual's mind-set plays a moderating role in preference over time. For subjects with a satisfying mind-set, preference was influenced by the increasing proximity of the event. However, for subjects with a maximizing mind-set, the influence of temporal distance is much more limited.

\section{EXPERIMENTS 2A AND 2B}

\section{Method}

Design and procedure. A total of 534 students at a large university in China were recruited to conduct experiment 2. There were 243 participants with valid sets of data in Experiment 2A (154 females, 89 males; $M_{\text {age }}=24.43, S D=6.277$ ) and 279 participants with valid sets of data in Experiment 2B ( 170 females, 109 males; $M_{\text {age }}=24.77, S D=8.753$ ). Both Experiment $2 \mathrm{~A}$ and $2 \mathrm{~B}$ adopted a $2 * 2$ between-subjects design based on temporal distance and mind-set. The dependent variable was the maximum effort (i.e., money in Experiment $2 \mathrm{~A}$ and time in Experiment 2B) that they would sacrifice to obtain the most desirable option.

In each experiment, participants were first asked to complete a mind-set priming task consisting of eight questions, which has been used successfully in recent studies (Ma \& Roese, 2014; Mao, 2016). In order to activate a satisfying mind-set, the questions were asked using the phrase "good enough" (e.g. "Among the five cities, which one do you think is good enough to visit?"), whereas to activate a maximizing mind-set, the wording was altered to "best" (e.g. "Among the five cities, which one do you think is the best place to visit?"). The effectiveness of the priming task was pretested on a group of respondents not involved in any of the main studies $(N=71$, 35 females, 36 males, $\left.M_{\text {age }}=20.25, S D=2.061\right)$. After completing the mind-set activation questions, participants were asked: "When deciding among the options, to what extent was your choice motivated by ___?" ( on a nine-point unnumbered scale, with the leftmost point labelled "choosing one I am satisfied with" and rightmost point "choosing the best out of the five options"). Responses were recoded to " 1 " to " 9 " during subsequent analysis, with higher scores indicating greater maximizing tendencies. As expected, compared with satisficers $(M=$ 4.56), those primed by a maximizing mind-set reported a higher motivation to select a best alternative $(M=6.67, F(1,69)=18.482, p<.001)$. In Experiment 3 and Experiment 4 , the same method was used to prime participants' mind-set. Therefore, we do not report it for the 
later experiments.

After the priming task, respondents were asked to imagine that they were going to travel in either 1 week (near future) or 1 year (distant future) and to read the descriptive material for two destination options. In Experiment 2A, the respondents were asked to indicate how much they would pay to visit a really desirable scenic mountain destination, if the cost of a less desirable one was 60 RMB (about US\$8.82 when Experiment 2A was conducted, as 1 US dollar was worth approximately $6.8 \mathrm{RMB}$ ). In Experiment $2 \mathrm{~b}$, respondents were asked to indicate how long they would be prepared to queue for entry at a really desirable theme park, if there was no waiting time at a less desirable alternative.

We repeated the same questions for the time manipulation check as for Experiment 1. Again, previous travel experience was used as a control variable for Experiments $2 \mathrm{~A}$ and $2 \mathrm{~B}$, and monthly disposable personal income was also recorded and used as a control variable for Experiment 2A.

\section{Results and discussion}

Seven participants from Experiment 2A were removed from the analysis because the money they wished to pay for the highly desirable scenic site ticket was more than 500 RMB (about \$73.53). Five participants from Experiment 2B were removed because four participants wished to wait for the highly desirable theme park for more than 300 minutes and one was confused by the task.

Money: A $2 \times 2$ between-subjects ANCOVA with previous travel experience and monthly disposable personal income as covariates was performed. The results showed a main effect of temporal distance $(F(1,237)=13.827, p<.001)$, mind-set $(F(1,237)=16.427, p<.001)$ and an interaction between temporal distance and mind-set $(F(1,237)=5.399, p=.021)$ on effort (money). The effect analysis suggested that temporal distance affected effort when a satisfying mind-set is activated $(F(1,238)=19.13, p<.001)$, whereby participants in the near future condition $(M=91.85)$ tended to spend less on a highly desirable option than participants in the distant future condition $(M=124.29)$. However, the main effect of temporal distance was not significant when the participants were primed with a maximizing mind-set stimulus $(F(1,238)$ $=0.74, p=.390$ ). 


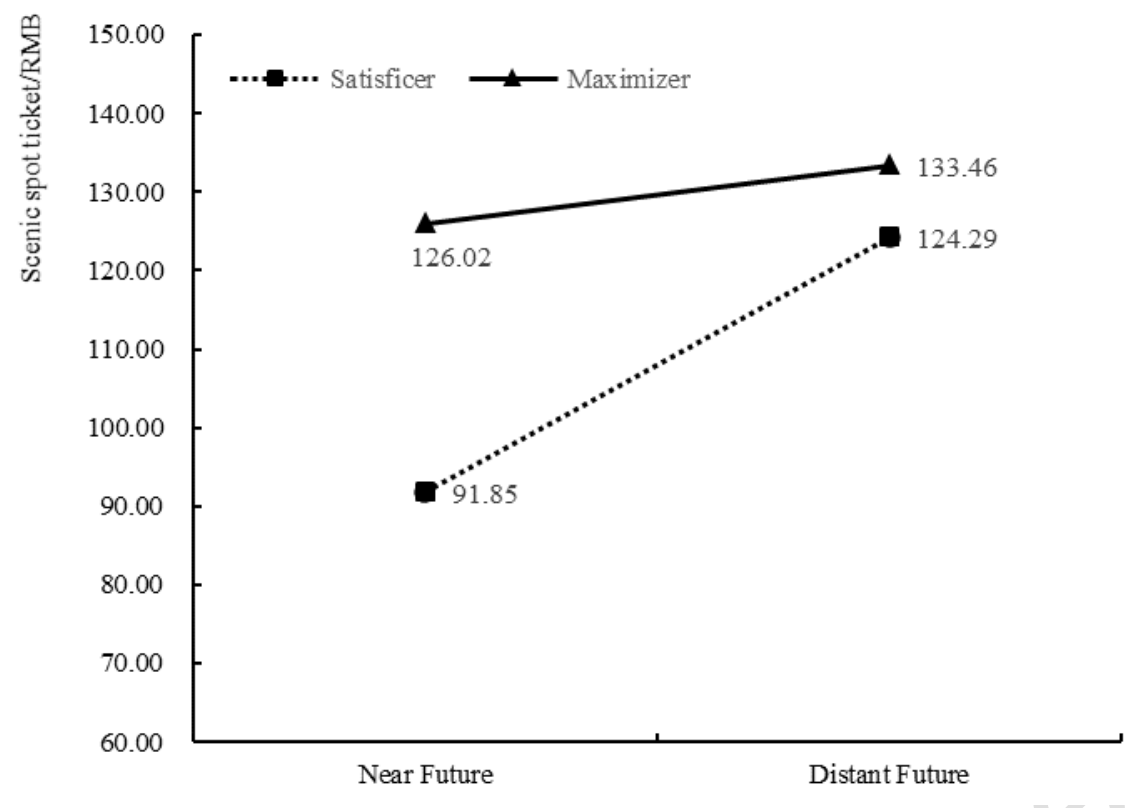

Notes: Covariates appearing in the model are evaluated at the following values: Previous travel experience $=1.880$, monthly disposable personal income $=2.430$

Figure 2. Experiment 2A: The maximum participants were willing to spend on highdesirability options across different temporal distances.

Time: The ANCOVA indicated significant temporal distance and mind-set main effects $(F(1$, $274)=14.290, p<.001 ; F(1,274)=13.174, p<.001)$ and a significant interaction $(F(1,274)$ $=4.057, p=.045$ ) on effort (waiting time). For participants with a satisfying mind-set, participants in the near future $(M=21.08)$ would wait less time than participants in the distant future $(M=44.03, F(1,275)=17.27, p<.001)$. For participants with a maximizing mind-set, the difference between near and distant future was not significant $(F(1,275)=1.62, p=.204)$.

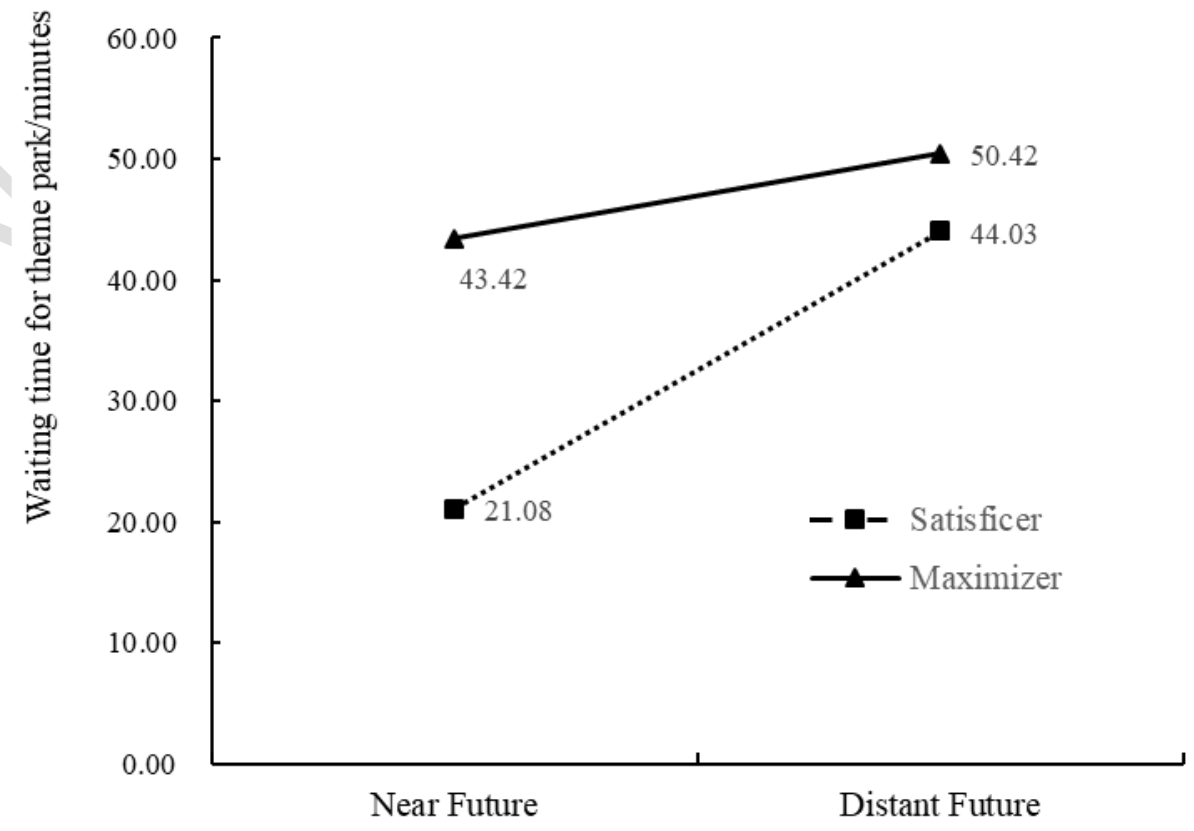


Notes: Covariate appearing in the model is evaluated at the following value: Previous travel experience $=1.950$

Figure 3. Experiment 2B: The maximum time participants were willing to wait for entry to a highly desirable option across different temporal distances.

In line with our theorization, the findings of Experiments $2 \mathrm{~A}$ and $2 \mathrm{~B}$ further supported hypothesis 2 , that both maximizers and satisficers are willing to make sacrifices to achieve the more highly desirable option when temporal distance is far. In a near future condition, however, satisficers make less effort to attain the highly desirable option and are more likely to compromise. In contrast, the effort maximizers would undertake to obtain the highly desirable option is not influenced by temporal distance and a tendency to compromise is not obvious. This experiment suggests that the reason for differences in the patterns of change in preference between satisficers and maximizers might be that they have different levels of willingness to sacrifice feasibility in pursuit of those values at different time distances.

An important issue in the foregoing experiments is the hypothetical nature of the choice scenarios, in order that we could manipulate temporal distance. In Experiment 3, we therefore extend our analysis to a realistic setting. This enables us to be more confident that temporal distance is an important factor driving the effects and not an effect of the imaginary scenarios used.

\section{EXPERIMENT 3}

\section{Method}

Design and procedure. The main study involved 223 participants ( 85 females, 138 males, Mage $=21.79, S D=1.379$ ) recruited from a different university to the previous experiments. Again, a $2 * 2$ between-subjects design with temporal distance and mind-set was used. The main dependent measure was the possibility of going to Tibet for the graduation trip. A higher score represents a higher possibility. A direct manipulation of temporal distance was adopted in this experiment by asking students about their intended graduation trips across different grades (junior students vs. senior students).

The participants first completed the maximizing or satisfying mind-set priming task, and were then required to read a descriptive paragraph about Tibet (see Appendix B). In the text, Tibet was introduced as an alternative option for the graduation trip and the text included information regarding its desirability and feasibility. Through our pretest with a sample of 51 males and 35 females, Tibet was considered a destination with high desirability $(M=4.83)$ but low feasibility $(M=3.95, F(1,170)=15.182, p<.001)$.

Afterwards, participants were asked to indicate the level of possibility for them of Tibet as a destination for their graduation trip, on a seven-point scale $(1=$ impossible, $7=$ very possible $)$. Questions on perceived temporal distance and demographic and previous travel experience followed. 


\section{Results and discussion}

A two-way between-subjects ANCOVA with participants' previous travel experience as a covariate showed a main effect of temporal distance $(F(1,218)=10.356, p=.001)$, of mindset $(F(1,218)=5.503, p=.020)$ and an interaction between temporal distance and mind-set $(F$ $(1,218)=4.164, p=.043)$. The simple effect analysis suggested that temporal distance affected the possibility of choosing Tibet as the destination for the graduation trip when a satisfying mind-set was activated $(F(1,219)=14.30, p<.001)$. The participants in the near future condition $(M=3.25)$ were less likely to choose to go to Tibet than participants in the distant future condition $(M=4.31)$. However, the main effect of temporal distance was not significant when participants were primed with the maximizing mind-set stimulus $(F(1,219)=0.32, p$ $=.571)$.

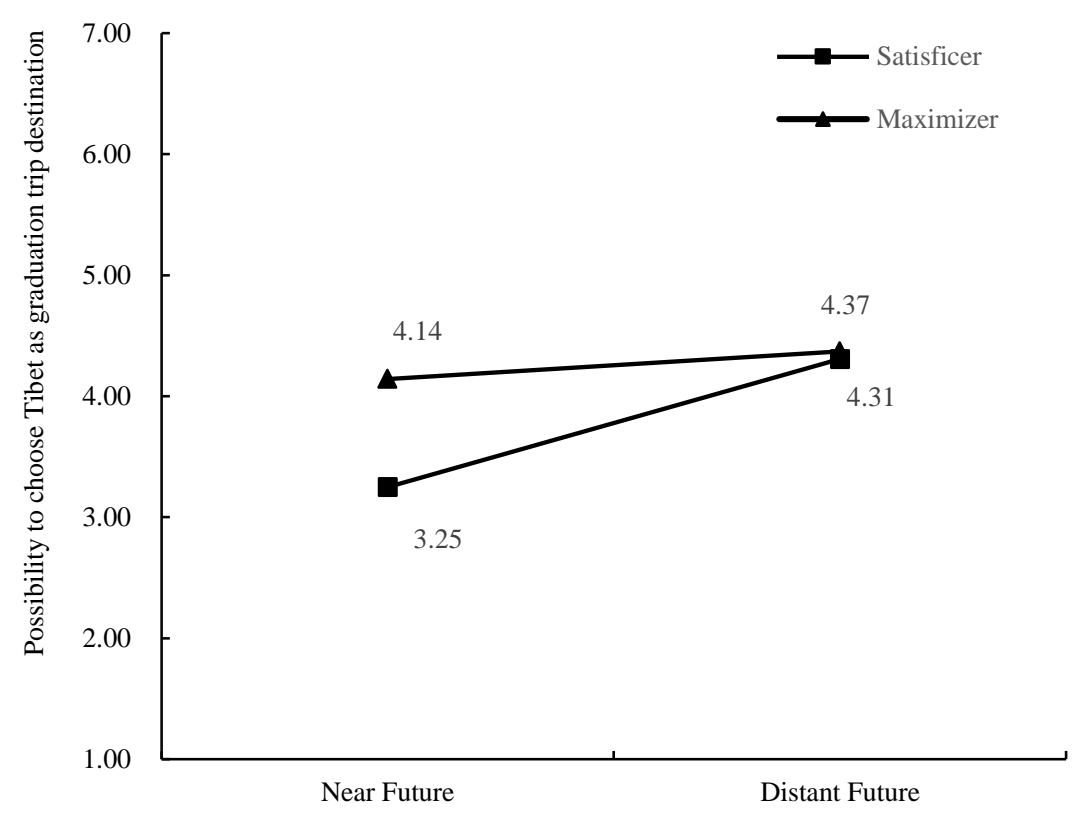

Notes: Covariate appearing in the model is evaluated at the following value: Previous travel experience $=1.684$

Figure 4. Experiment 3: The possibility that participants would choose Tibet as their graduation trip destination across different temporal distances.

Experiment 3 further tested hypothesis 2, and confirmed and increased the reliability of the overall results. One of the main challenges faced by destination choice research is the lack of experimental studies and the use of actual destinations in quantitative studies (Cohen, Prayag, \& Moital, 2014). By adopting an actual destination for the experiment and a direct manipulation of temporal distance, this research responds to those challenges.

The results of the previous experiments provide evidence for our hypothesis that tourists have a stronger preference for destinations with stronger feasible attributes the closer they get to a decision. Further, we show a boundary condition when tourists are maximizers or when their 
maximizing mind-set is activated through a priming task. Further questions remain, however. Why do maximizers display consistency, while satisfiers display inconsistency in preferences over time, when destination decisions normally involve trade-offs between desirability and feasibility? The results of Experiment 2 suggest that the reason underlying these effects seems to be related to individuals' perspectives on feasibility or their willingness to sacrifice feasibility to achieve more desirable destination options. Therefore, the goal of Experiment 4 is to investigate the mechanisms driving these effects.

\section{EXPERIMENT 4}

\section{Method}

Design and procedure. Chines people aged over 18 years were eligible for inclusion in this survey. In total, 345 participants were recruited online through SO JUMP (a popular online survey platform in China). Participants were randomly assigned to one cell of a 2 (time: near future vs. distant future) $* 2$ (mind-set: satisficer vs. maximizer) design. 74 nonserious participants were excluded because they failed to pass the instructional manipulation check and completion time check. 3 were removed from analysis due to gender and other information missing. This resulted in a final data set consisting of 268 respondents (126 females and 142 males). The average age of the valid sample was 31 years, ranging from 18 to 65 , and $78 \%$ of the participants had a monthly disposable personal income of over 2000 RMB (about \$294.12).

Unlike in the previous experiments, this study used images of real destinations to create a more vivid impression of destination desirability. The effectiveness of the pictures (desirability of destinations A and X, see Appendix C) and descriptions (feasibility of destination A and X) was pretested on a separate group of respondents not involved in any of the main studies $(N=$ 53, 33 females, 20 males, $M_{\text {age }}=20.86, S D=2.898$ ). After looking at the pictures and reading the descriptions of the destinations (as in Experiment 1), participants answered questions about their desirability and feasibility. Our manipulation of the feasibility and desirability of destinations A and X was successful: A $(M=5.34)$ was more desirable than $\mathrm{X}(M=4.62, F$ $(1,104)=10.705, p=.001)$ and the feasibility of $\mathrm{A}(M=4.15)$ was less than that of $\mathrm{X}(M=$ $5.62, F(1,104)=46.911, p<.001)$.

Firstly, the mind-set priming task used in Experiment 2 was utilized. Subsequently, respondents were asked to imagine that they are going for a holiday in either one week or one year and after a careful selection, two destinations remain (A and X). Five pictures of each destination were presented on one page to the respondents, followed by its textual descriptions relating to destination feasibility, as in Experiment 1.

Participants were then asked to rate the importance of budget airline tickets and the time involved to do trip planning on a seven-point scale ( $1=$ not important at all, $7=$ very important $)$. Subsequently, participants were asked to indicate their relative preference on a seven-point scale anchored at the preference of destination $\mathrm{A}(=7$, desirable but not feasible $)$ and destination $\mathrm{X}(=1$, feasible but not desirable). The two destinations (A or $\mathrm{X}$ ) were presented in a random order, and the preference scores were unified for further analyses; higher scores indicated 
higher preferences for the high-feasibility and low-desirability option. Finally, participants were asked about demographic characteristics and travel experiences.

\section{Results and discussion}

The main dependent measure was the relative preference between the high-feasibility and the high-desirability options. Note that higher scores represent greater preference for the higherfeasibility/lower-desirability option. A two-way between-subjects ANCOVA with participants' previous travel experience as the covariate showed a main effect of temporal distance $(F(1$, $263)=6.278, p=.013)$, of mind-set $(F(1,263)=8.800, p=.003)$ and an interaction between temporal distance and mind-set $(\mathrm{F}(1,263)=5.429, p=.021)$. Main effects analyses revealed a significant temporal distance effect when the subject's mind-set is manipulated as satisficer $(\mathrm{F}(1,264)=10.43, p=.001)$, but no effect in the maximizer group $(F(1,264)=0.01, p=.995)$.

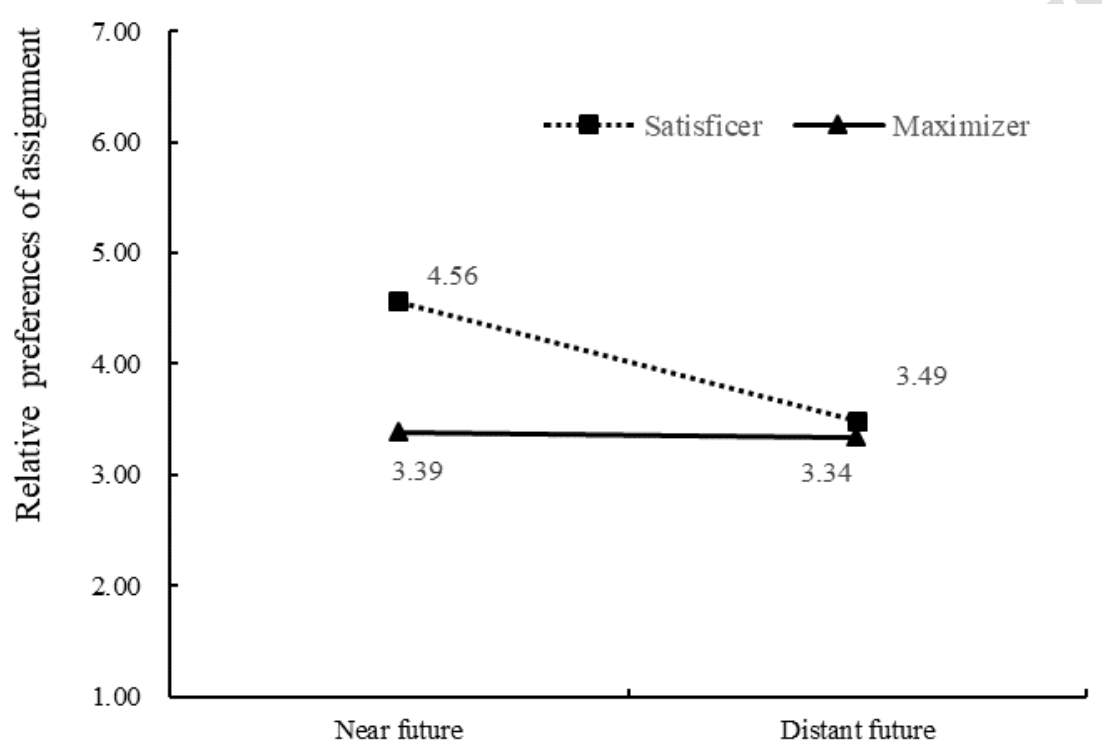

Notes: A higher score represents greater preferences for the higher-feasibility option. Covariate appearing in the model is evaluated at the following value: Previous travel experience $=2.340$.

Figure 5. Experiment 4: The relative preference of assignment across different temporal distances.

We followed the procedure suggested by Muller, Judd and Yzerbyt (2005) to test our mediated moderation hypothesis, with temporal distance as the independent variable, mind-set as the moderator, the importance of feasibility as the mediator, and participants' destination preferences as the dependent variable. Participants' destination preference (Model 1) and the importance of feasibility (Model 2) were regressed on temporal distance, mind-set, and their interaction. In Model 3, participants' destination preference was regressed on the same variables as in Model 1, but the importance of feasibility and its interaction with mind-set was added. In each equation, participants' previous travel experience was included as a control variable. 
As Table 1 shows, Model 1 indicates that the coefficient of the interaction between temporal distance $\times$ participants' mind-set is positively related to destination preference $(p<.050)$. Model 2 shows that the coefficient of the interaction between temporal distance $\times$ participant's mind-set is positively related to the importance of feasibility $(p<.050)$. In Model 3 , the importance of feasibility has a significant positive effect on participants' destination preference $(p<.050)$ and the coefficient of the interaction between temporal distance $\times$ participant's mindset is reduced to a non-significant level. This indicates that mind-set serves as a moderator in the relationship between temporal distance and destination preference, and this moderation is further fully mediated by the importance of feasibility. Therefore, we confirm this mediation effect on participants' destination preference. Specifically, for tourists with a satisfying mindset, near-future temporal distance leads to increased perception of feasibility importance, which enhances their preference for higher-feasibility destinations. On the other hand, for tourists with a maximizing mind-set, temporal distance has no significant influence on perception of feasibility importance or destination preference.

Table1. Results of the Mediated Moderation Test

\begin{tabular}{|c|c|c|c|c|c|c|}
\hline \multirow[t]{2}{*}{ Predictor } & $\begin{array}{l}\text { Model } 1 \\
\text { Preference }\end{array}$ & & $\begin{array}{l}\text { Model } 2 \\
\text { Importance of } \\
\text { feasibility }\end{array}$ & & $\begin{array}{l}\text { Model } 3 \\
\text { Preference }\end{array}$ & \\
\hline & $\begin{array}{l}\text { Standardized } \\
\text { Coefficients } \\
\text { Beta }\end{array}$ & $\mathrm{t}$ & $\begin{array}{l}\text { Standardized } \\
\text { Coefficients } \\
\text { Beta }\end{array}$ & $\mathrm{t}$ & $\begin{array}{l}\text { Standardized } \\
\text { Coefficients } \\
\text { Beta }\end{array}$ & $\mathrm{t}$ \\
\hline (Constant) & & 12.72 & & 15.33 & & 5.94 \\
\hline $\begin{array}{l}\text { Participant's } \\
\text { previous travel } \\
\text { experience }\end{array}$ & -0.090 & -1.50 & -0.07 & -1.10 & -0.08 & $\overline{1} .37$ \\
\hline Temporal distance & $-0.29 * * *$ & -3.38 & $-0.27 * *$ & -3.20 & $-0.24 * *$ & $\overline{2} .67$ \\
\hline Mind-set & $-0.32 * * *$ & -3.75 & $-0.28 * *$ & -3.33 & -0.16 & $\overline{0} .86$ \\
\hline $\begin{array}{l}\text { Temporal } \\
\text { distance*Mind-set }\end{array}$ & $0.24 *$ & 2.33 & $0.22 *$ & 2.13 & 0.19 & 1.88 \\
\hline $\begin{array}{l}\text { Importance of } \\
\text { feasibility }\end{array}$ & & & & & $0.19^{*}$ & 2.14 \\
\hline $\begin{array}{l}\text { Importance of } \\
\text { feasibility*Mind-set }\end{array}$ & & & & & -0.11 & $\overline{0} .64$ \\
\hline
\end{tabular}

Notes:* $p<.05, * * p<.01, * * * p<.001$.

A bootstrapping analysis also verified this mediated moderation. When participants exhibit a satisficer mind-set, the importance of feasibility mediated the relationship between temporal distance and destination preference $(95 \%$ confidence interval $(\mathrm{CI})=-1.555,-0.290)$. However, when participants held a maximizer mind-set $(95 \%$ CI $(-0.636$ to 0.579$)$ includes 0$)$, the mediating effect of the importance of feasibility is not significant. In this case, the interaction 
effect of temporal distance and mind-set on destination preference is transmitted through the importance of feasibility.

Consistent with Experiments 1 and 3, the results in Experiment 4 verified that temporal distance was a factor in participants' destination preference and confirmed that mind-set moderates the effect of temporal distance on destination preference. More importantly, our experiments also found that this moderating effect was mediated by the importance of feasibility and this provided a possible explanation for the first three sets of results. The mediated moderation analysis revealed why tourists with different mind-sets have different patterns of preference (in)consistency over time. Hence, hypothesis 3 is supported.

\section{DISCUSSION AND CONCLUSIONS}

\section{Theoretical implications}

According to the classic choice set model of destination choice (e.g. Um \& Crompton 1990; Decrop, 2010), tourists narrow down their choices from a large awareness set to a smaller consideration set to their final choice. During this process, plans move from fantasy to concrete reality (Decrop \& Snelder, 2004). However, many studies treat destination choice as a homogeneous process, without considering the possibility that preferences may be different from one stage to another (Li et al., 2017). This research provides quantitative evidence of how preferences can shift from desirable destinations to feasible destinations as temporal distance reduces. This finding corroborates the proposition of Karl and Reintinger (2017), who argued that individuals tend to respond favourably to positive attributes during a hypothetical stage of decision making and less favourably in a more demanding real context with situational constraints. As time approaches, the hypothetical trip becomes more and more realistic, which necessitates that tourists not only focus on the desirability of destinations but also on their feasibility.

According to leisure constraint theory, whether the intention results in actual behaviour is not dependent upon the absence of constraints, but rather upon successful negotiation of constraints (Jackson, Crawford, \& Godbey, 1993). From this perspective, destination selection can also be regarded as a negotiation between motivations and constraints. Desirability of a destination is one of the most important motivations driving tourist decisions whereas feasibility represents the extent to which tourists feel that they can alleviate the constraints. During this negotiation process, a variety of external interventions as well as internal factors play a role and even change the decision outcome (Lyu \& Oh, 2015). In marketing and consumer research, much attention has been paid to external interventions such as attention shifting (Hoch \& Loewenstein, 1991; Mischel et al.,1989), practising mental simulation (Zhao et al., 2007), and highlighting price information (Lee \& Zhao, 2014) and how such interventions offer valuable solutions for practitioners wishing to alter consumer preferences to achieve higher profits. However, less effort has been placed on exploring internal factors, such as personal traits, which also have a critical influence on preference consistency. Nevertheless, the investigation of internal factors may be more important from a social psychological stance because it enables us to better understand the diversity and complexity of human beings. 
It is possible to readily assume that people's general way of thinking (i.e. mind-set) would have more or less influence in this negotiation between desirability and feasibility. Luan and Li's (2017) study provides an important starting point for this question. Our own studies found that people with maximizing or satisfying mind-sets weigh the importance of feasible attributes differently, the latter placing more importance on feasibility. Thus, a further question raised is whether this difference in mind-set influences changes in preference patterns over time. Our results prove the moderating role of mind-set on decision makers' tendency towards preference inconsistency over time. More specifically, for a distant temporal event, both maximizers and satisficers prefer a desirable destination to a feasible one. At a close temporal distance, satisficers are more likely to change their preference from a desirable to a feasible destination, whereas the maximizers would try their best to overcome the constraints and stick to their original preferred destination.

The moderating role of mind-set revealed in this study not only serves to increase consumers' long-term satisfaction by understanding and manipulating their patterns of preference change (Lee \& Zhao, 2014), but also adds to the explanatory power of CLT. Moreover, we extend the analysis of Luan and Li (2017) by considering temporal distance. By comparing decision makers' preference at different time points, the findings complement mind-set theory by indicating that differences in preference between maximisers and satisficers are not significant for distant temporal events. More importantly, the maximizing mind-set mitigates the influence of temporal distance on preference inconsistency regarding desirability and feasibility, whereas a satisficing mind-set increases the inclination to change preference.

\section{Managerial implications}

This study has important managerial implications. First, it urges destination marketing organizations to consider customizing promotional material to take account of the different phases of the planning stages of tourists' decision making. In general, desirable images of the destination should be emphasized for tourists at an early stage. But when tourists get closer to the date on which they book their vacation, desirable features should be complemented by information on the practical necessities (attributes) to ensure the overall level of attractiveness is suitable for both satisficers and maximizers.

Secondly, a tourism destination should ensure clarity of messages regarding its desirable attributes together with feasibility characteristics, to ensure optimization of destination positioning and effective market targeting. Established European destinations provide examples that combine highly desirable features together with utility attributes, such as proximity to major Northern European and Scandinavian markets, convenient and modern transport infrastructure, and year-round product availability. Differentiated marketing campaigns targeting segments with different mind-sets should be encouraged. For example, last-minute discounts are likely to be more attractive to satisficers than to maximizers, who are more likely to respond to messaging based on performance, competence mastery, or goal achievement for example.

Finally, the ultimate goal of marketing is to change customers' tastes and create demand. 
Therefore, the real success of destination advertising lies not only in attracting tourist interest by providing information, but also in changing their preference from dislike or nonconsideration, to consideration, preference and liking. This study shows that mind-set is a critical factor that influences destination preference, which can be activated through relevant stimuli. Therefore, destinations could target tourists' mind-sets to activate a desired state to facilitate decision making. For instance, Tibet, as a highly desirable but also highly unfeasible destination, would perhaps benefit by advertising to activate the maximizing mind-set.

\section{Limitations and future study}

This study has several limitations in terms of research scope, which indicates the need for further research. First of all, the study examined the dynamics of preference only in terms of desirability and feasibility, and the range of attributes investigated should be expanded in future studies. Besides, other aspects of preference (e.g. utility vs. hedonism; abstract vs. concrete) and even the preference function (compensatory strategy vs. non-compensatory strategy) could also vary at different stages of decision making. More experimental studies are needed to reveal the dynamic patterns of tourist destination choice. Furthermore, this research concentrates on one important factor (i.e. mind-set) that influences tourists' patterns of preference change. Destination choice, however, is a very complicated process with a multitude of different influencing factors. Other factors such as travel companion play a significant role in preference (Li et al., 2017), and may also have an impact on tourists' preference consistency over time.

Regarding methodology, the stimulus materials regarding destination desirability and feasibility employed in the experiments were newly developed and need to be examined and improved. Furthermore, in the first three experiments, student samples were used instead of a sample representing the whole population, which may affect the representativeness of the findings (Calder, Phillips, \& Tybout, 1981). However, whether it is acceptable to use a student sample depends on whether the sample is theoretically appropriate for the questions researchers want to address (Vargas, Duff, \& Faber, 2017). We argue that the sample does satisfy this criterion. Indeed young, well-educated Chinese people are one of the most important tourism market segments. Additionally, college students have the advantage of being able to understand and interpret relatively complicated experimental tasks. In addition, in Experiment 4, an online experimental survey was conducted with a non-student sample to replicate the findings, which increased the external validity of the research. However, the sample size in Experiment 4 does not allow us to investigate the demographic features that might be used to distinguish between satisficers and maximizers, though this could be explored in future studies.

\section{REFERENCES}

Ankomah, P. K., Crompton, J. L., \& Baker, D. (1996). Influence of cognitive distance in vacation choice. Annals of Tourism Research, 23(1), 138-150.

Araña, J. E., \& León, C. J. (2016). Are tourists animal spirits? Evidence from a field experiment exploring the use of non-market based interventions advocating sustainable tourism. Journal of Sustainable Tourism, 24(3), 430-445. 
Baskin, E., Wakslak, C. J., Trope, Y., \& Novemsky, N. (2014). Why feasibility matters more to gift receivers than to givers: A construal-level approach to gift giving. Journal of Consumer Research, 41(1), 169-182.

Basoglu, K. A., \& Yoo, J. J. E. (2015). Soon or later? The effect of temporal distance on travel decisions. Journal of Travel \& Tourism Marketing, 32(sup1), S62S75.

Bettman, J. R., Luce, M. F., \& Payne, J. W. (1998). Constructive consumer choice processes. Journal of consumer research, 25(3), 187-217.

Calder, B. J., Phillips, L. W., \& Tybout, A. M. (1981). Designing research for application. Journal of consumer research, 8(2), 197-207.

Chaminuka, P., Groeneveld, R. A., Selomane, A. O., \& Van Ierland, E. C. (2012). Tourist preferences for ecotourism in rural communities adjacent to Kruger National Park: A choice experiment approach. Tourism management, 33(1), 168-176.

Ciná,V.Z.(2012).Tourism marketing: A game theory tool for application in arts festivals. Tourism Economics, 18, 43-57.

Cohen, S. A., Prayag, G., \& Moital, M. (2014). Consumer behaviour in tourism: Concepts, influences and opportunities. Current issues in Tourism, 17(10), 872-909.

Dar-Nimrod, I., Rawn, C. D., Lehman, D. R., \& Schwartz, B. (2009). The maximization paradox: The costs of seeking alternatives. Personality and Individual Differences, 46(5-6), 631-635.

Decrop, A. (2010). Destination choice sets: An inductive longitudinal approach. Annals of Tourism Research, 37(1), 93-115.

Decrop, A., \& Snelders, D. (2004). Planning the summer vacation: An adaptable process. Annals of Tourism Research, 31(4), 1008-1030.

Dhar, R., \& Kim, E. Y. (2007). Seeing the forest or the trees: Implications of construal level theory for consumer choice. Journal of Consumer Psychology, 17(2), 96-100.

Dolnicar, S., \& Ring, A. (2014). Tourism marketing research: Past, present and future. Annals of Tourism Research, 47, 31-47.

Doran, R., Hanss, D., \& Øgaard, T. (2017). Can Social Comparison Feedback Affect Indicators of Eco-Friendly Travel Choices? Insights from Two Online Experiments. Sustainability, 9(196), 1-15.

Dryglas, D., \& Salamaga, M. (2017). Applying destination attribute segmentation to health tourists: A case study of Polish spa resorts. Journal of Travel \& Tourism Marketing, 34(4), 503-514.

Eyal, T., Liberman, N., Trope, Y., \& Walther, E. (2004). The pros and cons of temporally near and distant action. Journal of personality and social psychology, 86(6), 781-795.

Friedman, D., \& Sunder, S. (1994). Experimental methods: A primer for economists. Cambridge University Press, s, Cambridge, U.K. 
Go, F., \& Zhang, W. (1997). Applying importance-performance analysis to Beijing as an international meeting destination. Journal of Travel Research, 35(4), 4249.

Goodman, J. K., \& Malkoc, S. A. (2012). Choosing here and now versus there and later: The moderating role of psychological distance on assortment size preferences. Journal of Consumer Research, 39(4), 751-768.

Haahti, A. J. (1986). Finland's competitive position as a destination. Annals of tourism research, 13(1), 11-35.

Highhouse, S. (2009). Designing experiments that generalize. Organizational Research Methods, 12(3), 554-566.

Hoch, S. J., \& Loewenstein, G. F. (1991). Time-inconsistent preferences and consumer self-control. Journal of consumer research, 17(4), 492-507.

Hsu, T. K., Tsai, Y. F., \& Wu, H. H. (2009). The preference analysis for tourist choice of destination: A case study of Taiwan. Tourism management, 30(2), 288-297.

Iyengar, S. S., Wells, R. E., \& Schwartz, B. (2006). Doing better but feeling worse: Looking for the "best" job undermines satisfaction. Psychological Science, 17(2), 143 150 .

Jackson, E. L., Crawford, D. W., \& Godbey, G. (1993). Negotiation of leisure constraints. Leisure sciences, 15(1), 1-11.

Jeng, J., \& Fesenmaier, D. R. (2002). Conceptualizing the travel decision-making hierarchy: A review of recent developments. Tourism analysis, 7(1), 15-32.

Kah, J. A., Lee, C. K., \& Lee, S. H. (2016). Spatial-temporal distances in travel intention-behavior. Annals of Tourism Research, 57, 160-175.

Karl, M., \& Reintinger, C. (2017). Investigating Tourists' Destination Choices-An Application of Network Analysis. European Journal of Tourism Research, 15, 112130.

Kim, J., Kim, P. B., Kim, J. E., \& Magnini, V. P. (2016). Application of construallevel theory to promotional strategies in the hotel industry. Journal of Travel Research, 55(3), 340-352.

Lee, K. K., \& Zhao, M. (2014). The effect of price on preference consistency over time. Journal of Consumer Research, 41(1), 109-118.

Li, C., McCabe, S., \& Li, X. (2017). Digging deeper into decision-making of Chinese long-haul outbound tourists: a two-stage preference estimation approach. Journal of Destination Marketing and Management, 6(3), 267-275.

Li, C., McCabe, S., \& Song, H. (2017). Tourist choice processing: evaluating decision rules and methods of their measurement. Journal of Travel Research, 56(6), 699-711.

Liberman, N., \& Trope, Y. (1998). The role of feasibility and desirability considerations in near and distant future decisions: A test of temporal construal theory. Journal of personality and social psychology, 75(1), 5-18. 
Liberman, N., Sagristano, M. D., \& Trope, Y. (2002). The effect of temporal distance on level of mental construal. Journal of experimental social psychology, 38(6), 523-534.

Luan, M., \& Li, H. (2017). Good enough - compromise between desirability and feasibility: An alternative perspective on satisfying. Journal of Experimental Social Psychology, 70, 110-116.

Lyu, S. O., \& Oh, C. O. (2015). Bridging the conceptual frameworks of constraints negotiation and serious leisure to understand leisure benefit realization. Leisure Sciences, 37(2), 176-193.

Ma, J., \& Roese, N. J. (2014). The maximizing mind-set. Journal of Consumer Research, 41(1), 71-92.

Mao, W. (2016). When one desires too much of a good thing: The compromise effect under maximizing tendencies. Journal of Consumer Psychology, 26(1), 66-80.

McCabe, S., Li, C., \& Chen, Z. (2016). Time for a radical reappraisal of tourist decision making? Toward a new conceptual model. Journal of Travel Research, 55(1), 3-15.

Mischel, W., Shoda, Y., \& Rodriguez, M. L. (1989). Delay of gratification in children. Science, 244(4907), 933-938.

Muller D, Judd C M, Yzerbyt V Y. When moderation is mediated and mediation is moderated. Journal of personality and social psychology, 2005, 89(6): 852-863.

Nenkov G Y, Morrin M, Schwartz B, et al. (2008). A short form of the maximization scale: Factor structure, reliability and validity studies. Judgment and Decision making, 3(5), 371-388.

Raudenbush, S. W., Bryk, A. S., \& Congdon, R. (2004). Hlm 6 for windows [computer software]. Skokie, IL: Scientific Software International, Inc.

Sarman, I., Scagnolari, S., \& Maggi, R. (2016). Acceptance of life-threatening hazards among young tourists: A stated choice experiment. Journal of Travel Research, 55(8), 979-992.

Schwartz, B.,Ward, A., Monterosso, J., Lyubomirsky, S., White, K., \& Lehman, D. R. (2002). Maximizing versus satisfying: Happiness is a matter of choice. Journal of Personality and Social Psychology, 83(5), 1178-1197.

Seddighi, H. R., \& Theocharous, A. L. (2002). A model of tourism destination choice: a theoretical and empirical analysis. Tourism management, 23(5), 475-487.

Smallman, C., \& Moore, K. (2010). Process studies of tourists' decisionmaking. Annals of Tourism Research, 37(2), 397-422.

Soman, D. (2004). The effect of time delay on multi-attribute choice. Journal of economic psychology, 25(2), 153-175.

Tan, W. K. (2018). From fantasy to reality: a study of pre-trip planning from the perspective of destination image attributes and temporal psychological distance. Service Business, 12(1), 65-84. 
Thaler, R. (1981). Some empirical evidence on dynamic inconsistency. Economics letters, 8(3), 201-207.

Trope, Y., \& Liberman, N. (2003). Temporal construal. Psychological review, 110(3), 403-421.

Trope, Y., \& Liberman, N. (2010). Construal-level theory of psychological distance. Psychological Review, 117(2), 440-463.

Trope, Y., Liberman, N., \& Wakslak, C. (2007). Construal levels and psychological distance: Effects on representation, prediction, evaluation, and behavior. Journal of consumer psychology, 17(2), 83-95.

Um, S., \& Crompton, J. L. (1990). Attitude determinants in tourism destination choice. Annals of tourism research, 17(3), 432-448.

Um,S., \& Crompton,J L. (1992). The roles of perceived inhibitors and facilitators in pleasure travel destination decisions. Journal of travel research, 30(3), 18-25.

Vargas,P.T., Duff, B.R., \& Faber, R. J. (2017). A practical guide to experimental advertising research. Journal of Advertising, 46(1), 101-114.

Zhao, M.,Hoeffler,S.,\&Zauberman,G. (2007). Mental simulation and preference consistency over time: The role of process-versus outocused thoughts. Journal of Marketing Research, 44(3), 379-388. 
ALWAYS BEST OR GOOD ENOUGH? The effect of 'mind-set' on preference consistency over time in tourist decision making

\section{Appendix:}

Appendix A. Desirability and Feasibility Manipulations of Destination A and X in Experiment 1

\begin{tabular}{|l|l|}
\hline \multicolumn{1}{|c|}{ Destination A } & \multicolumn{1}{c|}{ Destination X } \\
\hline $\begin{array}{l}\text { Destination A is your favourite seaside resort, } \\
\text { where the sea water is crystal clear, the } \\
\text { sunshine is brilliant and beautiful, and the } \\
\text { beach is very soft and clean. }\end{array}$ & $\begin{array}{l}\text { Destination X is one of your favourite seaside } \\
\text { sunshine is well enough, and the beach is soft. }\end{array}$ \\
\hline $\begin{array}{l}\text { Activities here are rich and varied. Apart from } \\
\text { common beach activities, e.g. sunbathing, } \\
\text { swimming, fishing, boating, you can also } \\
\text { enjoy yourself surfing, rock climbing, } \\
\text { barbecue and bonfire party. }\end{array}$ & $\begin{array}{l}\text { Although there's not a lot of activities here, only } \\
\text { swimming, fishing, and boating, you feel that is } \\
\text { enough for you to enjoy. }\end{array}$ \\
\hline $\begin{array}{l}\text { Because of language barriers, you need have } \\
\text { to spend at least half-a-day concentrating } \\
\text { yourself on reading travel guides online to } \\
\text { adapt to the local life. }\end{array}$ & $\begin{array}{l}\text { Thus without any preparation in advance, you } \\
\text { and there are many Chinese customer support. } \\
\text { can easily adapt yourself to the local life. }\end{array}$ \\
\hline $\begin{array}{l}\text { The air ticket to Destination A is fully priced } \\
\text { without any discount. }\end{array}$ & $\begin{array}{l}\text { The air ticket to Destination X is on sale and you } \\
\text { can enjoy } 50 \% \text { discount. }\end{array}$ \\
\hline
\end{tabular}


Appendix B. Desirability and Feasibility Descriptions of Tibet in Experiment 3

Tibet is full of beautiful and imposing natural scenery, e.g. the vast land, snow capped mountains towering surges, holy and pure lakes, in groups cattle and sheep, Galsang flowers booming everywhere.

Tibet has a mysterious and splendid folk culture, e.g. the holy temple, the three step knock believers, wind flying colorful prayer flags, solemn and sacred chanting.

Tibet abounds in delicious food with plateau features, e.g. the fragrant barley wine and butter tea, chewy beef jerky, delicious stir-fried and braised lamb, hearty and very warming tsampa.

Buildings in Tibet have charming artistic and are permeated with the glorious history of Tibetan Buddhism culture, e.g. the glorious and palatial palaces and temples, exquisite carved pillars and painted murals, magnificent Fanlun, red-and-white temple walls.

However, most tourists who arrive at Tibet will have light or heavy altitude reaction. As the ultraviolet radiation is very strong here, skin suntans and peels easily.

As Tibet is a vast, sparsely populated area, traffic is not very convenient. Especially, during the rainy season, the roads are muddy, and even much likely to be cut down by storms.

The accommodation conditions of Tibet are relatively backward. No matter the number of hotels, room facilities, sanitary conditions or service quality, none of them can compare with eastern China.

Because Tibet supplies are very scarce, the consumption level is relatively high, whether it is accommodation, catering service or shopping. Touring at Tibet is very time-consuming and most tourists spend more than 10 days in generally.

\section{Appendix C. Desirability Manipulations of Destination A and X in Experiment 4}




\section{Destination A}
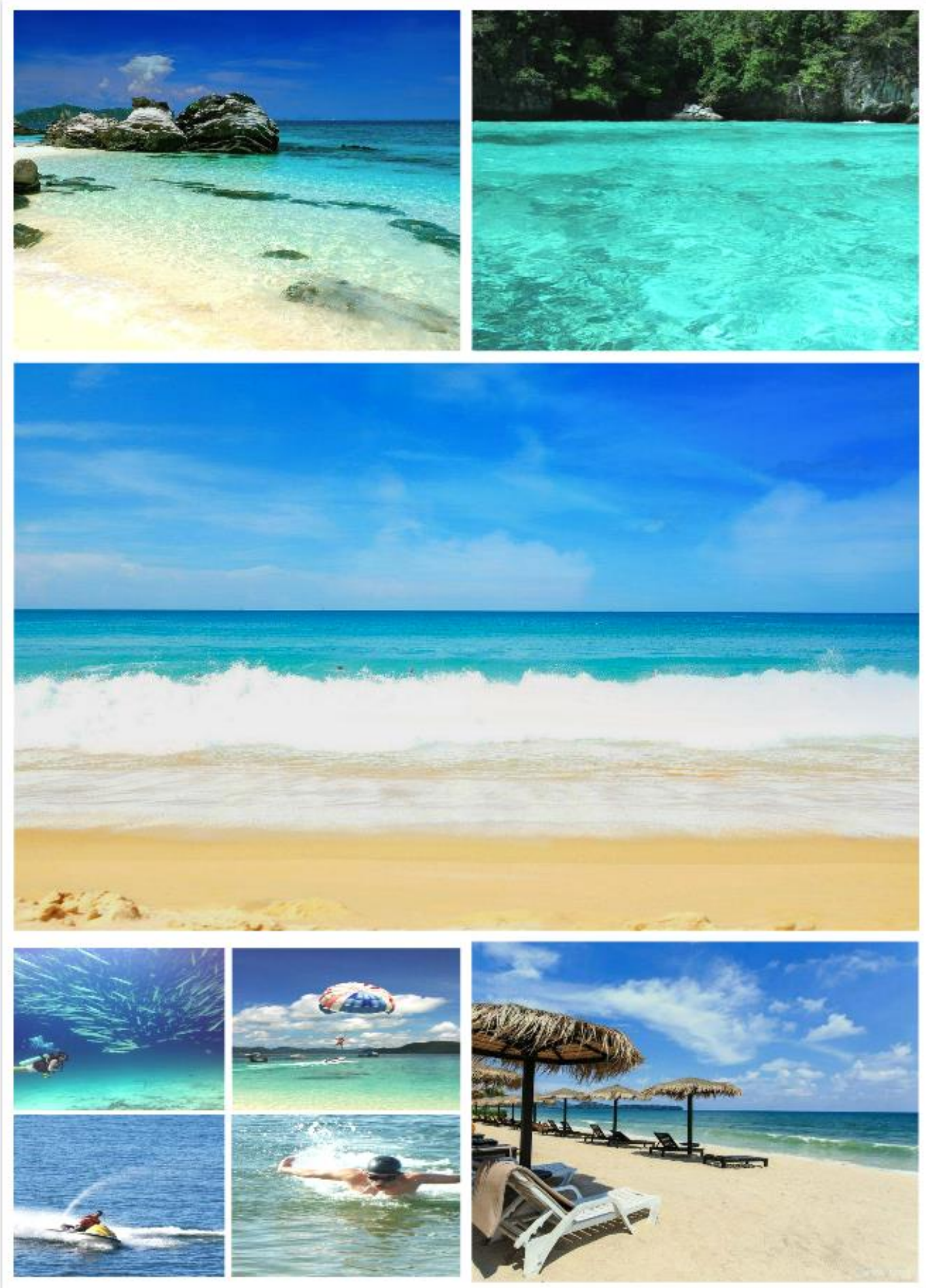

Destination $\mathrm{X}$ 

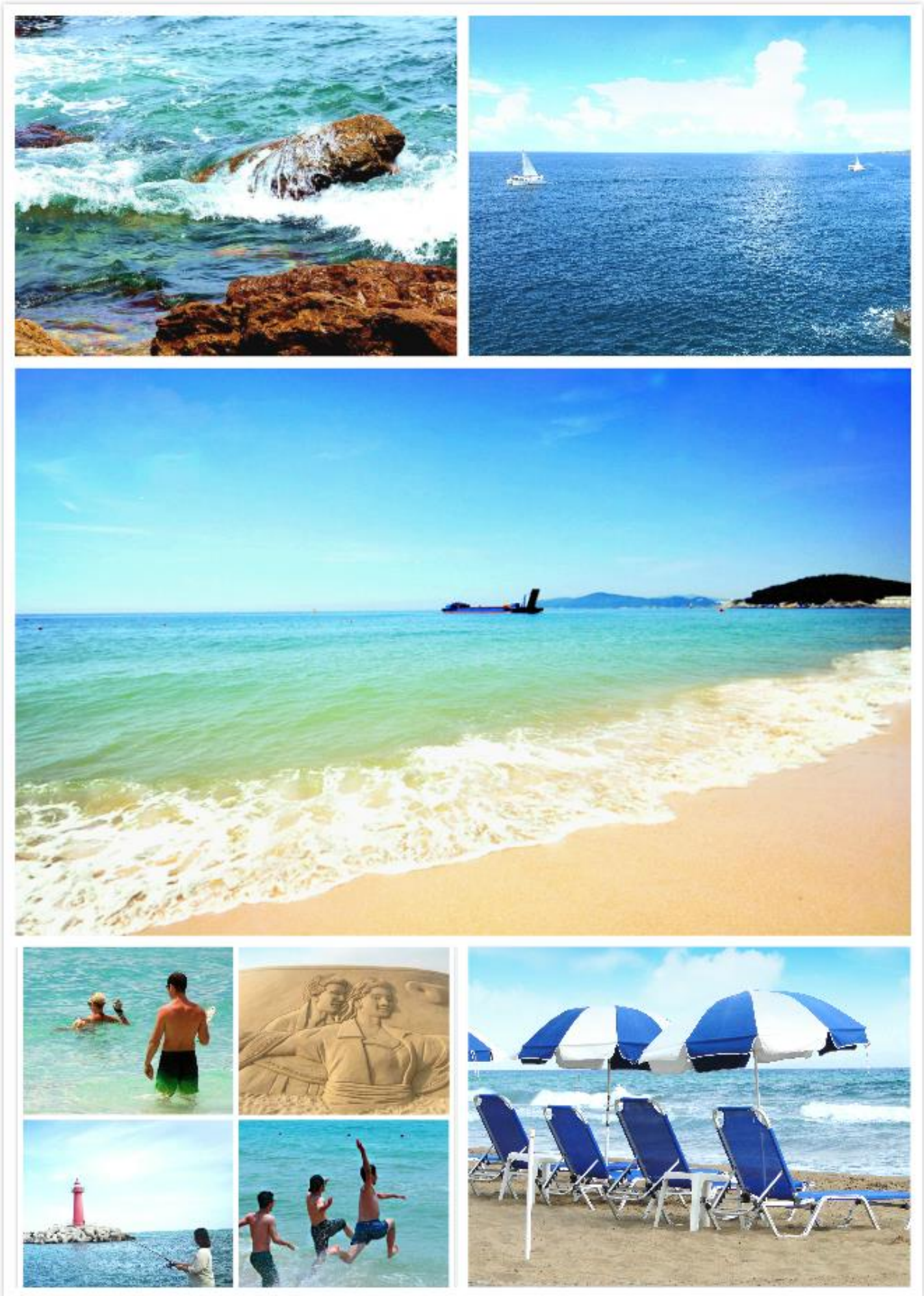

Notes: All the pictures were downloaded from http://image.baidu.com/. 